\title{
Seroprevalence of Infectious Makers on Blood Donors at the Blood Bank of Bertoua Regional Hospital (Cameroon)
}

\author{
Marcellin Guiaro Ndoe, ${ }^{1, *}$, Octavie Danielle Moankong Fak ${ }^{1}$, Armel Herve Nwabo Kamdje ${ }^{1}$, \\ Charles Fokunang Ntungwen ${ }^{2}$, Alexandre Michel Njan Nloga ${ }^{1}$ \\ ${ }^{1}$ Department of Biomedical Sciences, Faculty of Science, University of Ngaoundere, Ngaoundere, Cameroon \\ ${ }^{2}$ Faculty of Medicine and Biomedical Sciences, University of Yaounde I, Yaounde, Cameroon
}

\section{Email address:}

d.nokosore@yahoo.fr (M. G. Ndoe)

\section{To cite this article:}

Marcellin Guiaro Ndoe, Octavie Danielle Moankong Fak, Armel Herve Nwabo Kamdje, Charles Fokunang Ntungwen, Alexandre Michel Njan Nloga. Seroprevalence of Infectious Makers on Blood Donors at the Blood Bank of Bertoua Regional Hospital (Cameroon). Science Journal of Public Health. Vol. 3, No. 5, 2015, pp. 757-760. doi: 10.11648/j.sjph.20150305.33

\begin{abstract}
The present study was aimed at optimizing the transfusion security of the patients, we determined the seroprevalence of transferable infections by the blood transfusion notably the HIV, hepatitis B, hepatitis C and the syphilis among the blood donors at the blood bank of regional hospital of Bertoua to reduce meaningfully their impact in hospitable environment. We performed a prospective transversal survey on 429 Blood donors from the $1^{\text {st }}$ January 2013 to $1^{\text {st }}$ January 2014. We included 371 men (86.48\%) and 38 women (13.52\%). During this survey, we noted that, the most large part of blood donation was given by family members of patients with a seroprevalence of $58.04 \%$ compared to volunteers donors $(23.78 \%)$ and remunerated donors (18.18\%). The infections seroprevalence of human immunodeficiency virus (HIV), hepatitis B virus (HBV), hepatitis C virus (HCV) and Syphilis has been estimated to $5.13 \%, 6.76 \%, 4.2 \%$ and $0.46 \%$ respectively. These results showed that it was necessary to put an accent on the pre-donation stages; cross-examination of the blood donor (research of information able to annul the blood donation), verification of the biological parameters (blood type rhesus, the hemoglobin rate and research of the infectious makers) to reduce the residual risks of these infections by the blood transfusion.
\end{abstract}

Keywords: Seroprevalence, Infectious Markers, Blood Donors

\section{Introduction}

Blood transfusion is a process, which consists to administrate a donor's blood to a recipient (allo-transfusion) or of the recipient to himself (auto-transfusion). Blood can be administrated in various forms: total blood, plasma, concentrated red blood cells, white blood cells, thrombocytes or other fractions extracted from plasma [1; 2]. The transfusion security is assured by a mastery of all stages of the transfusion chain of the donor to the recipient. It started at the time of blood donation with the objective in term of security not to harm the donor or the recipient. It continues to all stages permitting the preparation of blood products, notably the biological qualification of the donation. Finally, the immunological security is assured by the research of the best compatibility of the blood types [1; 2]. The different types of transferable infections during blood transfusion are between other: the parasitic, bacterial, and viral infections. The infections sexually transferable as the infection with human immunodeficiency virus (HIV), the infection with $\mathrm{B}$ hepatitis (HBV), the infection with $\mathrm{C}$ hepatitis (HCV) and the syphilis constitutes a major problem of public health currently because their frequency during the blood transfusions, their complications and the socio-economic consequences that they generate [3]. A survey achieved on the blood donors in Democratic Republic of Congo revealed a seroprevalence of $4.7 \%$ with human immunodeficiency virus, $5.4 \%$ with hepatitis B and $3.7 \%$ with syphilis [4] and another made to Cameroon, at the blood bank of Laquintinie hospital of Douala returned a seroprevalences of $7.89 \% ; \quad 6.91 \% ; \quad 2.2 \% ; \quad 7.90 \%$ respectively for the human immunodeficiency virus, hepatitis B, hepatitis C, and syphilis [5]. These studies show the strong impact of these sexually transferable infections during blood transfusion. What would be the gravity of this problem in the East Cameroon Region among the blood donors at the blood bank of Bertoua Regional hospital? Very few epidemiological data concerning these infections 
are available in Cameroon. It is why, we judged necessary and appropriate to make this survey with the aim to optimize the transfusion security of patients in hospitable environment, more precisely to reduce meaningfully the infection risk during blood transfusion at the blood bank of Bertoua Regional hospital.

\section{Materials and Methods}

We carried out a prospective transversal survey from January 1st, 2013 to January 1st, 2014 on all people received for the blood donation (family members of patients, remunerated donor and volunteer's donor) at the blood bank of Bertoua regional hospital and filling all criterias concerning the blood transfusion. We considered like donor, all person aged from 15 to 65 years, not having given of blood at least three months preceding his arrival and we excluded of our survey all women in pregnancy state, breast feeding state and mentrual state. All candidates to the blood donation have been submitted to a cross-examination on the epidemiological data (sex, ages, etc.) and the biological analysis achieved on their samples of blood before blood transfusion as the HIV test, $\mathrm{HBV}$ test, $\mathrm{HCV}$ test and the VDRL test, allowed us to determine the infection cases of HIV, HBV, HCV, and syphilis. The donors have been informed verbally of the existence of biological analysis, of the anonymous character of the survey and the fact that their medical analysis results will be communicated to each of them personally for medical handling if necessary. The introverted data were typed and analyzed with the help of the Excel software 2010 and R software version-2.13.0. We used the chi-square test to compare the percentages and the Accepted significance was fixed to $5 \%$.

\section{Results}

During this survey, we counted 429 blood donors, divided in three main groups (family members of patients, remunerated and volunteer's donor). Among these 429 blood donors, we counted 371 men $(86.48 \%)$ and 58 women $(13.52 \%)$.

\subsection{Patients Distribution According to the Age Groups}

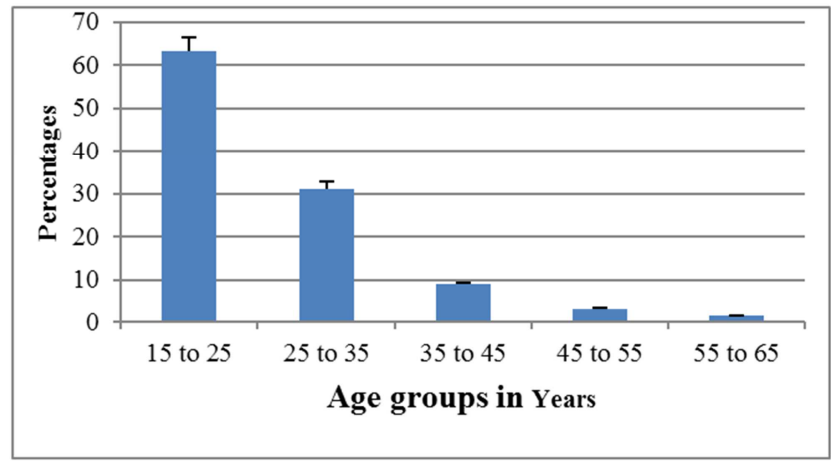

Graph 1. Graphical representation showing de patient's distribution according to the age groups.
The average age was 21 years, with ages ranging between 15 to 65 years. The age groups of 15 to 25 years, consisted of 25 to 35 years, were the most represented with respective percentages of $63.32 \%$ and $23.13 \%$. The percentages differences was statistically meaningful with:

$$
\mathrm{X}^{2}=564.03, \mathrm{df}=4, \mathrm{P} \text {-value }<2.2 \mathrm{e}^{-16}(\text { Graph } 1)
$$

\subsection{Patient's Distribution According to the Different Sexes}

We counted 371 men $(86.48 \%)$ and 58 women $(13.52 \%)$. The masculine sex was the most represented with a sexratio of 6.39 in favor of men (Graph 2).

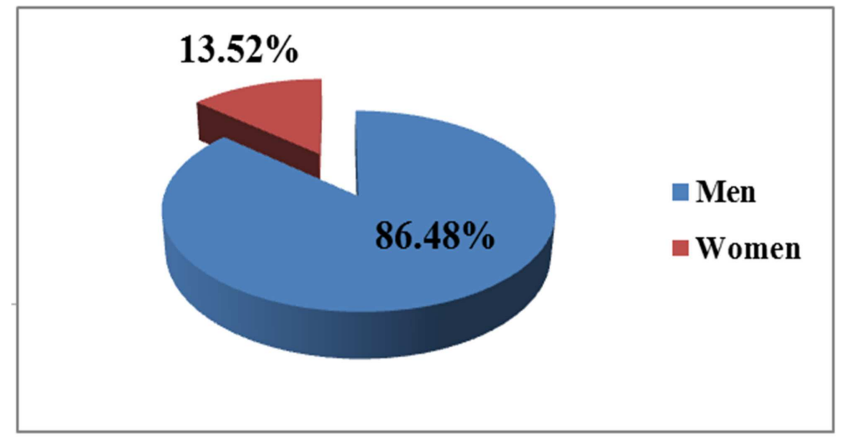

Graph 2. Graphical representation showing the patient's distribution according to different sexes.

\subsection{Patient's Distribution According to the Blood Donor Groups}

The family members were the most represented among the blood donors with a rate of $58.04 \%$. The percentages difference was statistically meaningful with:

$$
\mathrm{X}^{2}=119.87, \mathrm{df}=2, \mathrm{P} \text {-value }<2.2 \mathrm{e}^{-16}(\text { Graph } 3) .
$$

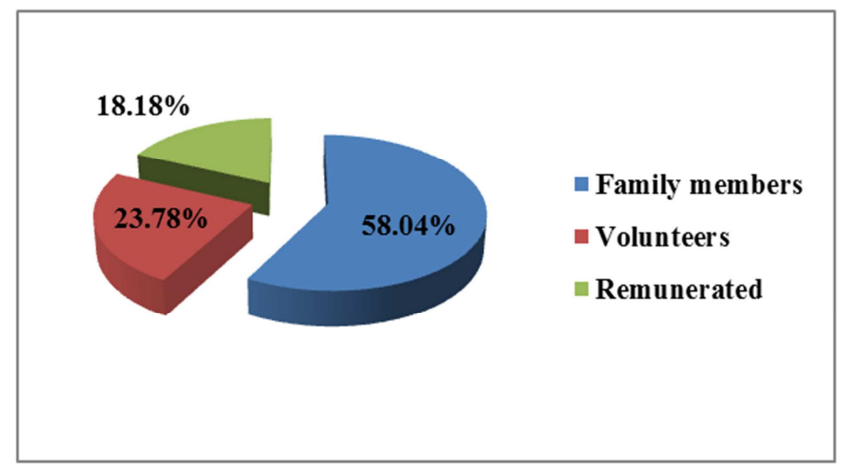

Graph 3. Graphical representation showing the patient's distribution according to the blood donor groups.

\subsection{Seroprevalence of Different Infectious Markers According to the Age Groups}

The seroprevalences of the infectious makers was more raised in the age group of 15 to 25 years (Table 1).

The seroprevalences difference of infectious makers according to the age groups was statistically meaningful with: $\mathrm{X}^{2}=12.09, \mathrm{df}=4, \mathrm{P}$-value $=0.01$. 
Table 1. Showing the seroprevalence of different infectious markers according to the age groups.

\begin{tabular}{llllll}
\hline \multirow{2}{*}{ Age groups } & \multicolumn{5}{l}{ Seroprevalences of Infectious markers } \\
\cline { 2 - 6 } & HIV & HBV & HCV & Syphilis & Total \\
\hline $15-25$ & 2.80 & 4.42 & 2.10 & 0.23 & 9.55 \\
$25-35$ & 1.40 & 1.64 & 1.87 & 0 & 4.91 \\
$35-45$ & 0.7 & 0.47 & 0 & 0 & 1.17 \\
$45-55$ & 0 & 0.23 & 0.23 & 0.23 & 0.69 \\
$55-65$ & 0.23 & 0 & 0 & 0 & 0.23 \\
Total & 5.13 & 6.76 & 4.2 & 0.46 & 16.55 \\
\hline
\end{tabular}

\subsection{General Prevalence of Blood Donors According to the Infectious Makers}

The hepatitis B virus (HBV) were the most represented among the blood donors at the blood bank of Bertoua Regional hospital with a seroprevalence of $6.76 \%$ compared to HIV (5.13\%), HCV (4.20\%) and Syphilis (0.46\%). The seroprevalences difference was not statistically meaningful with: $\mathrm{X}^{2}=4.41, \mathrm{df}=3, \mathrm{P}$-value $=0.2($ Graph 4$)$.

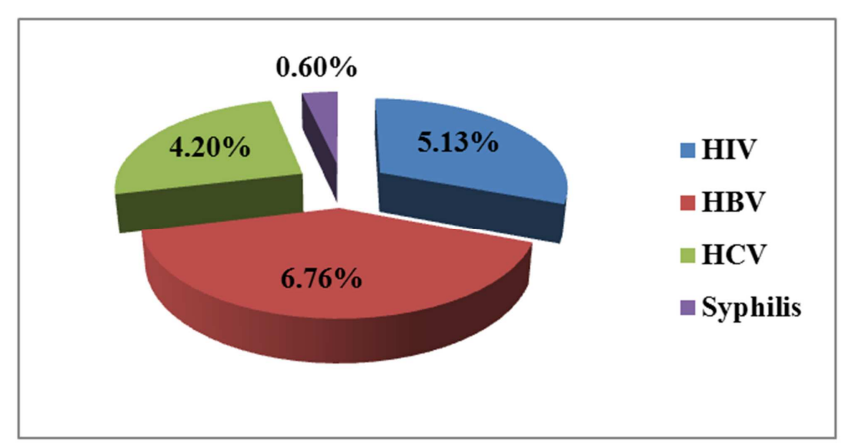

Graph 4. Graphical representation showing the general prevalence of blood donors according to the infectious makers.

\subsection{Limits of the Study}

The scientific honesty allows us to admit that this study was not perfect, and thus, its limits must be specified. The percentage of patients affected by the infectious makers was very weak compared to the number of blood donors appearing in our survey. Consequently, the seroprevalences of these different infectious makers found at the blood bank of Bertoua Regional hospital, cannot spread to the whole East Region.

\section{Discussion}

It was question for us in this survey, to determine the seroprevalence of sexually transferable infections as the HIV, $\mathrm{HVB}, \mathrm{HCV}$ and syphilis among the blood donors at the blood bank of Bertoua Regional hospital. We noted during this survey that, the age groups of 15 to 25 years and 25 to 35 years were the most represented with percentages of $63.32 \%$ and $23.13 \%$ respectively (Graph 1 ). These results come closer of those gotten by Pirsou in 2008 on the blood donors at the central hospital of Yaounde, where they found a percentage of $63.31 \%$ for the age group of 18 to 27 years [6] and also of those found by Guekeng in 2010 at the hospitable and academic center of Yaounde (HACY) that to added on 55.7\% for the age group of 21 to 30 years [7]. These age groups constitute the young population. It would explain itself by the fact that youth is the most solicited for the blood donation and having for motivation to benefit from the exemption from payment of the sexually transferable infections test [6] and also by the fact that the young represent the biggest fraction of the Cameroonian population as developing country.

The sex-ratio was of 6.39 in favor men (Graph 2). The predominance of the masculine sex $(86.48 \%)$ on the feminine sex $(13.52 \%)$, in our population of survey corroborates to the results found by Pirsou in 2008 among the blood donors at the Central hospital of Yaounde and by Geukeng in 2010 among the blood donors at the Hospitable and Academic Center of Yaounde (HACY) [6-7]. This masculine predominance would explain itself in part by some physiological states of women which prohibited the blood donation temporarily as the menstrual, pregnancy and the breast feeding [8]. It is also due to the fact that, men are more solicited due to the relation to their better health [9] and the fact that the blood donation is reserved to the men in our African society [6].

Family members among the blood donors were more represented (58.04\%) that the volunteer's donor $(23.78 \%)$ and remunerated donor (18.18\%) (Graph 3). This situation doesn't escape the one met in the survey achieved by Sodahlon in 2004 in Africa sub-of the Sahara to Togo where the replacement blood donation from the family members of patient reached $80 \%$ [10] and $88 \%$ in Cameroon; it is also the case of the survey of Elira-Dokekias led in 2002 in Brazzaville that had shown a percentage of $63 \%$ of this donor group. The predominance of the family members of patient in our survey can explain itself by the fact that, there are more easy to spot and available that the other blood donors groups.

The seroprevalence of infectious makers (HIV, HBV, HCV and Syphilis) was more raised in the age group of 15 to 25 years with as respective percentage of $2.80 \%, 4.42 \%$, and $2.10 \%$ and $0.23 \%$ (Table 1 ). It could explain itself by the fact that the life period of 15 to 25 years is also a period of intense sexual activity favorable to the infections transmission. Contrary to our works, ACKAH in a survey achieved at the venereal diseases center (VDC) of Abidjan in 1990, had revealed that $46.4 \%$ of serological positive for the HIV recruited themselves in the age group of 20 to 29 years [11]. These numbers move away from those found in our survey. However, we did not find a statistical link between the age of blood donors and the serology.

The summing up of the seropositivity of blood donors in our survey showed a rate raised of the seropositivity of hepatitis B virus with a rate of $6.76 \%$ compared with HIV, hepatitis C virus and syphilis which have respective rates of $5.13 \% ; 4.2 \%$ and $0.46 \%$ (Graph 4) what bring us to suggest that the Bertoua city to see the East region is in endemic zone, this number comes closer of the one found in the survey led to Kinshasa Est in Democratic Republic of Congo by Mbendi in 2001 where the seroprevalence of the HBs antigen was 9.2\%. This result is verified because it has been proven that, the prevalence of HBs antigen is more important in black Africa with an average of 9 [10]. It could explain itself by the fact that the illness and the mode of contamination are not well known. 


\section{Conclusion}

The present survey in spite of its limits shows that the transferable illnesses constitute a factor-limiting essential of the blood transfusion in black Africa. It was question for us to determine the seroprevalence of the infections to HIV, hepatitis $\mathrm{B}$, hepatitis $\mathrm{C}$ and syphilis among the blood donors to reduce the transmission risk of these infections by the blood transfusion at the blood bank of Bertoua Regional hospital. At the term of this survey, we found a seroprevalence of $5.13 \%$, $6.76 \%, 4.2 \%$ and $0.47 \%$ respectively for the infections to HIV, hepatitis B virus, hepatitis $\mathrm{C}$ virus and Syphilis among the blood donors in this hospital. These infections are all very dangerous and therefore their pre-transfusion screening test must be systematic. This measure is necessary in spite of the present indirect basis of the screening techniques. If the HIV virus preoccupies the cares establishments and blood transfusion, the screening test of the other viruses (Hepatitis B and C) and syphilis should make itself on all blood pockets before their delivery.

\section{Authorship Contribution}

All authors contributed to the designing, preparation, editing, and final review of the manuscript.

\section{Acknowledgement}

Authors thank the collaborators of their respective institutions for the comments on the manuscript.

\section{References}

[1] Nguyen, Y.Ozier. 2008. Risques transfusionnels Réanimation. J Hepatol 17: 326-338.

[2] Aubry P. BobinP. Soc.Pathol. Exot C. 2008. Lèpre et syndrome de reconstitution immunitaire au cours du sida. Bull., 101, 58-59 Médicales Nationales.., pp. 78-89.
[3] Hud. J. kane, M. A. Heyman D.L. 1991. Transmission of HIV, hepatitis virus and other blood borne pathogens in health care settings: a review of risk factors and guidelines for prevention. Bull. World Health Organ. 69: 6237.

[4] Lunel F, Mariotti M, Crestar Petal. 1995 Comparative study of conventional and novel strategies for the detection of hepatitis $\mathrm{C}$ virus RNA in serum: amplicor, branched-DNA, NASBA and in house PCR. J Virol Methods. 54: 159-71.

[5] Watanabe. J, Matsumoto C, Shimada Tetal. 1993. Predictive value of screening tests for persistent hepatitis C virus infection evidenced by viremia. Vox Sang. 65: 199-203

[6] PIRSOU. 2008. Evaluation du risque résiduel de l'hépatite B chez les donneurs de sang à l'Hôpital central de Yaoundé, thèse de doctorat en médecine.

[7] Geukeng Elvige. 2010. Risque infectieux résiduel de l'hépatite virale B au Centre Hospitalier et Universitaire de Yaoundé : Mémoire de master II en immunologie médicale.

[8] Kakou S. 1996. Etude de la prévalence des activités transfusionnelles en gynéco obstétrique à propos de 1956 cas collegiés au CHU de Treichville de 1993 à 1994. Th. Méd., Abidjan.

[9] Tayou C, Diarra A, Yahaya R, Hakizimana M, Nguessan A, Mbensa G. 2009. Characteristics of blood donors and donated blood in Sub-saharan francophone Africa. Transfusion. 49: $\mathrm{p}$ 1592-1599.

[10] Martin Luther Koanga Mogtomo, Sylvie Louandji Pomekong, Honnore Fotsokuate, Annie Ngono Ngane. 2004. Détection des agents infectieux dans les banques de sang de Douala. département de $\mathrm{BCH}$ faculté des sciences Université de Douala.

[11] Ackah. A.N. 1991. Contribution à l'étude de l'association MST et infection à VIH dans les Centres Antivénériens à Abidjan. Thèse Med: Abidjan. 